\title{
Lecionação em Optometria e Ciências da Visão durante e depois da crise da COVID-19
}

\author{
https://doi.org/10.21814/uminho.ed.24.10
}

\section{Paulo R.B. Fernandes}

Paulo Rodrigues Botelho Fernandes (ORCID: 0000-0002-3921-6357) é Professor Auxiliar do Departamento de Física da Escola de Ciências da Universidade do Minho, membro do Centro de Física e Diretor da Licenciatura em Optometria e Ciências da Visão da mesma Universidade.

\section{Rute J. Macedo de Araújo}

Rute J. Macedo-de-Araújo (ORCID: 0000-0003-3664-4273) leciona como docente na área disciplinar de Optometria da Universidade do Minho e trabalha como optometrista, sendo assistente de investigação no Clinical and Experimental Optometry Research lab (CEORLab) desde 2013. Tem desenvolvido investigação em lentes de contacto, nomeadamente lentes de contacto especiais, irregularidades corneais, qualidade ótica do olho humano, resposta eletrofisiológica da retina e distorção luminosa.

\section{Madalena Lira}

Maria Madalena Cunha Faria Lira (ORCID: 0000-0001-5564-0097) é Professora Auxiliar do Departamento de Física da Escola de Ciências da Universidade do Minho e membro do Centro de Física. É ainda coordenadora do programa Erasmus da área de Optometria e Coordenadora da Linha estratégica de Investigação Assessment and Enhancing Visual Performance do Centro de Física.

\section{António Queirós}

António Queirós Pereira (ORCID: 0000-0003-1045-4455) é Professor Auxiliar na área disciplinar de Optometria e Ciências da Visão (OCV) do Departamento de Física da Escola de Ciências da Universidade do Minho. Foi diretor de curso da licenciatura em Optometria e Ciências da Visão entre 2013 e 2017. 


\section{José M. González-Méijome}

José M. González Méijome (ORCID: 0000-0001-9050-4170) é Professor Catedrático na área disciplinar de Optometria e Ciências da Visão (OCV) do Departamento de Física da Escola de Ciências da Universidade do Minho. É presentemente o responsável pelo Programa Doutoral de OCV. Em 2016 recebeu o prémio de Optometrista Internacional do Ano pela Universidade Politécnica da Catalunha e, em 2018, foi agraciado com o prémio de Mérito Científico da UMinho. 


\section{RESUMO}

O ano 2020 deveria ser memorável para todos os profissionais e docentes da área das ciências da visão pelo facto de 20/20 ser uma referência padrão que se assume como sinónimo de uma visão adequada, por vezes mal denominada como os " $100 \%$ de visão". Ao invés, será recordado como uma das piores, senão a pior, crise sanitária, económica e talvez social para várias gerações nascidas na segunda metade do século XX e no século XXI. O ensino da Optometria e Ciências da Visão (OCV) tem características muito particulares sendo uma área fortemente técnica e ao mesmo tempo clínica, envolvendo uma elevada carga letiva de prática laboratorial e prática clínica de procedimentos e técnicas de exame, diagnóstico e tratamento de anomalias oculares. A reação da Área Disciplinar de OCV no contexto pandémico foi imediata, à semelhança do resto da Universidade do Minho. Seguiu-se um processo de aprendizagem com uma forte articulação entre os seus docentes e potencializando a partilha de experiências e recursos pedagógicos. Para isso contribuíram as diferentes estratégias de formação acelerada implementadas pela UMinho através do Gabinete de Apoio ao Ensino (GAE). Passada a etapa mais crítica, este artigo faz uma reflexão sobre os aspetos que consideramos mais relevantes e que contribuíram para manter o ensino ativo e com o maior aproveitamento possível para os estudantes na obtenção dos seus objetivos e resultados de aprendizagem. Comparamos a nossa abordagem com aquela seguida para a mesma área noutros contextos europeus e apresentamos ainda uma reflexão sobre aqueles aspetos que entendemos que devem ser retidos para o futuro num contexto de normalidade pós-COVID-19 ou de nova normalidade e que passará por uma articulação progressiva entre o ensino presencial e não presencial, síncrono e assíncrono, mas sempre dentro daquilo que uma área como esta possa permitir mantendo-o igualmente efetivo.

\section{INTRODUÇÃO}

A área disciplinar de Optometria e Ciências da Visão (OCV) está enquadrada no Departamento de Física (DF) da Escola de Ciências (EC) da Universidade do Minho (UMinho). Formalmente criada em 2010, integra os docentes com maior vinculação à lecionação dos cursos de Optometria, quer sejam especialistas em Optometria quer sejam docentes com outros percursos formativos dentro do mesmo departamento. 
A UMinho é atualmente a única Instituição de Ensino Superior (IES) em Portugal a lecionar formação de primeiro ciclo (C1 - Licenciatura de Optometria e Ciências da Visão - LOCV e suas predecessoras desde 1988), segundo ciclo (C2- Mestrado em Optometria Avançada - MOA desde 2009) e terceiro ciclo (C3 - Programa Doutoral em Optometria e Ciências da Visão - PDOCV desde 2013). Assegura ainda 4 cursos na modalidade de Ensino a Distância (EaD), experiência cujo início remonta a 2015.

$\mathrm{O}$ ensino em OCV tem particularidades que importa destacar. Ao longo de todo o percurso formativo existe a integração de uma forte componente de ciências da natureza e da vida com a componente de prática clínica. É objetivo dotar os alunos da licenciatura não apenas de conhecimentos avançados de ótica, visão e áreas afins, como também de várias competências clínicas específicas para a realização de consultas de avaliação e compensação da visão, através de métodos optométricos, não médicos nem cirúrgicos ${ }^{1}{ }^{2}$. Os alunos adquirem a sua formação, conhecimentos e competências através de aulas teóricas, teórico-práticas e práticas laboratoriais. Nas aulas laboratoriais são treinados os procedimentos clínicos optométricos fundamentais - sendo imprescindível a prática dos procedimentos entre colegas ou até mesmo em pacientes reais em contexto de formação mais avançada.

No treino das suas competências clínicas, a interação entre os alunos nas aulas práticas requer proximidade física (Figura 1), o que limita em grande medida a realização de atividades letivas num contexto pandémico como o que vivemos.

1 European Diploma in Optometry: Syllabus, learning outcomes and clinical/practical competencies. The European Council of Optometry and Optics (ECOO). 2017.

2 Global Competency-Based Model of Scope of Practice in Optometry. Patricia M Kiely, Robert Chappel Ed. World Council of Optometry. 2015. 


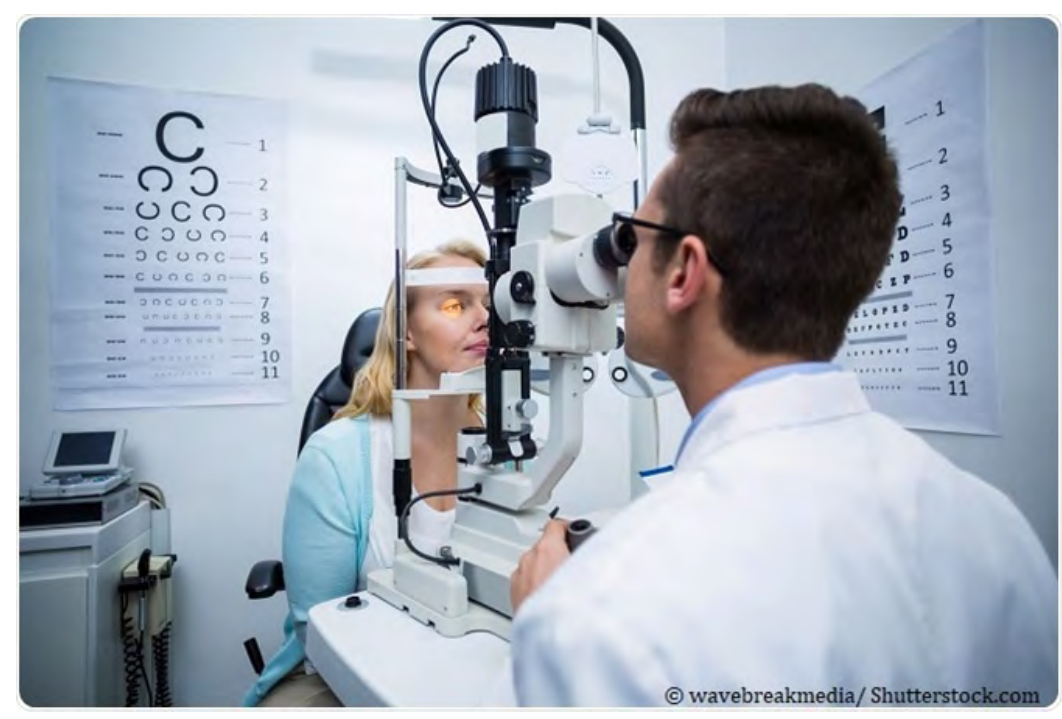

Figura 1. Uma situação típica numa consulta optométrica para a qual os alunos de optometria são treinados (Khetrapal A. What does an optometrist do? Disponível em https://www.news-medical.net/health/What-does-an-optometrist-do.aspx, Acedido em 15 de junho de 2020).

\section{CRISE DA COVID-19}

A crise sanitária provocada pelo SARS-CoV-2 que produz a doença COVID-19 atingiu a UMinho na primeira semana de março, sendo decretado o encerramento das instalaçóes no Campus de Gualtar onde funcionam os cursos da área de OCV a partir do dia 7 de março (Despacho RT-25/2020). Nos dois dias seguintes, decorreram já aulas síncronas online, através da plataforma Blackboard (Bb) e as suas ferramentas Bb Collaborate e $\mathrm{Bb}$ Collaborate Ultra, em unidades curriculares do MOA, estando no final dessa semana já em vigor diversos despachos reitorais decretando a lecionação online. Rapidamente esta experiência se estendeu às restantes UCs do MOA e restantes ciclos formativos da área de OCV (Licenciatura e PDOCV). Inicialmente, a maioria dos docentes optou pela lecionação online síncrona através da plataforma $\mathrm{Bb}$ dos conteúdos teóricos e teórico-práticos programados no início do semestre, de modo a cumprir com o programa teórico mesmo impossibilitados de o fazer presencialmente. Os docentes adaptaram-se a esta nova metodologia de ensino e, tendo em conta a situação de disseminação do SARS-CoV-2 à data, a 26 de março foram também iniciadas as atividades de substituição das aulas práticas laboratoriais. Estas aulas - usualmente lecionadas em regime presencial - foram adaptadas pelos docentes ao novo modelo formativo de regime não presencial. 
Desde o primeiro momento as sugestóes, interações e formações prestadas pelo Gabinete de Apoio ao Ensino (GAE) foram cruciais para o bom funcionamento das aulas síncronas online. Desde ajudas tão simples como marcar as aulas através da Bb Collaborate Ultra, permitindo maior facilidade de acesso aos alunos, apoio na elaboração de diferentes formas de avaliação online, até aos cursos de formação e adaptação das diferentes modalidades de ensino à distância que rapidamente se implementaram nas semanas seguintes ${ }^{3}{ }^{\mathrm{e}}$. Apesar de vários docentes da área de OCV já se encontrarem familiarizados com a modalidade de ensino à distância, pela relação e participação com os cursos anteriormente referidos (EaD), esta nova situação foi uma aprendizagem constante para todos, tendo sido necessário reformular conteúdos e formatos das aulas, principalmente das aulas de substituição teórico-práticas e práticas laboratoriais.

\section{EXPERIÊNCIAS OCV UMINHO}

À semelhança do que já é prática no ensino de Optometria em algumas instituições internacionais ${ }^{56}$, foram utilizadas diversas ferramentas de ensino e diferentes estratégias de lecionação. Em contexto de aulas síncronas com componente letiva teórica, teórica prática e de prática laboratorial, algumas das seguintes estratégias passaram a tornar-se habituais para a grande maioria dos docentezs da área de OCV:

- Disponibilização com antecedência aos alunos dos novos conteúdos programáticos e formatos;

- Gravação das aulas, sendo possível aos alunos a visualização, de forma flexível

3 Formatos: Síncrono ou Assíncrono. Quais as (des)vantagens de cada formato? Manuel João Costa. Centro IDEA-UMinho, Publicação: 16 de março 2020.

4 Construir um teste/exame de consulta. Elsa Costa e Silva, Manuel João Costa. Centro IDEA-UMinho, Publicação: 14 de abril 2020.

5 Gupta VK, Gupta VB (2016). Using Technology, Bioinformatics and Health Informatics Approaches to Improve Learning Experiences in Optometry Education, Research and Practice. Healthcare (Basel). 4(4):86. Published 2016 Nov 15. https://doi.org/10.3390/healthcare4040086.

6 Choudhury B, Gouldsborough I (2010). Gabriel S. Use of interactive sessions and e-learning in teaching anatomy to first-year optometry students. Anat Sci Educ. 3(1):39-45. https://doi.org/10.1002/ase.123. 
e adaptada ao seu horário, de todos os conteúdos lecionados, todas as participações e questões colocadas pelos colegas durante a sessão síncrona;

- Incentivo à participação dos alunos durante as aulas síncronas, para responder a perguntas diretas, comentários ou esclarecimento de dúvidas, através do sistema de voz (microfone) ou do chat existente na plataforma Bb Collaborate Ultra;

- Partilha de conteúdos (ficheiros, vídeos, imagens, casos clínicos) entre todos os docentes, de modo a tornar as aulas síncronas online mais completas e interativas; foi criado um centro de partilha de conteúdos que pudessem servir vários docentes em várias UCs;

- Gravação em formato vídeo de diversos procedimentos práticos de laboratório pelos docentes com o intuito de demonstrar e discutir os mesmos com os alunos em aulas síncronas;

- Utilização de vídeos de procedimentos e simuladores virtuais de anatomia ocular, lentes de contacto e procedimentos laboratoriais ${ }^{7,8 ~ e ~}$;

- Sempre que possível, nas aulas de substituição ou apoio da componente laboratorial, estiveram presentes todos os docentes da UC para uma maior interação com os alunos, melhor partilha de conhecimentos e experiências clínicas;

- Criação de um Fórum de discussão em cada UC, permitindo aos alunos troca de experiências e dúvidas fora do horário de funcionamento das aulas síncronas;

- Para tornar as aulas síncronas online mais dinâmicas e interativas, muitos docentes recorreram à realização de quizzes em contexto de aula síncrona. Estes quizzes, para além de motivar os alunos e de criar uma dinâmica interessante à aula, tinham também como objetivo aferir as competências adquiridas durante

\footnotetext{
7 International Association of Contact lens Educators (IACLE): $\underline{\text { https://iacle.org. }}$

8 Instituto Alcon: http://www.institutoalcon.com.

9 Acosta ML, Sisley A, Ross J, et al. (2018). Student acceptance of e-learning methods in the laboratory class in Optometry. PLoS One. 13(12):e0209004. Published 2018 Dec 13. https://doi.org/10.1371/journal. pone.0209004.
} 
a aula e identificar os pontos de maior dificuldade para os alunos, de modo a serem aprofundados em aulas futuras. Estes quizzes foram em alguns casos realizados através da ferramenta existente na própria Bb Collaborate Ultra, ou utilizando outras plataformas online tal como o Mentimer ou Kaboot, entre outros;

- Nas UCs com forte componente de avaliação e decisão clínica, foram incluídos diversos casos clínicos para análise e discussão dos mesmos com os alunos de forma a desenvolver o seu pensamento clínico e utilização dos conceitos no diagnóstico diferencial das situaçôes clínicas para minimizar a falta de contacto clínico dos mesmos;

- Trabalhos de pesquisa sobre relatos de casos clínicos publicados em revistas da especialidade e posterior apresentação pelos alunos aos colegas e docentes através da plataforma $B b$ Collaborate;

- Simulação de interação paciente-profissional em contexto de confinamento através da realização de vídeos entre distintos alunos, ou com membros do seu âmbito familiar (prévia informação e consentimento) com recurso a telemóveis, plataformas eletrónicas, etc.;

- Elaboração de minitestes no início da aula com 4 a 5 perguntas e resolução através da $B b$ Collaborate Ultra ou da plataforma $B b$ que foram utilizados como elementos de avaliação contínua dos alunos, mas que tinham como objetivo adicional fomentar a sua introdução aos conteúdos a serem lecionados. Estes minitestes normalmente incidiam sobre protocolos de práticas laboratoriais previamente fornecidos aos alunos, para que estes o estudassem antes da aula.
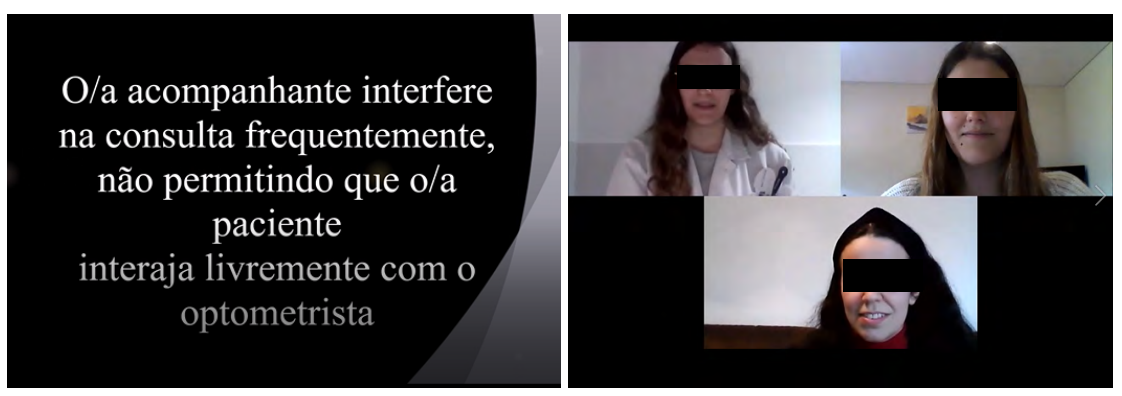

Figura 2. Recorrendo a uma plataforma de gravação de vídeo com o telemóvel, três alunas do curso de licenciatura simulam o procedimento de anamnese em que uma aluna entrevista uma mãe e a sua filha no âmbito da consulta optométrica. 


\section{A RESPOSTA DOS ALUNOS}

Pelo seu número, pelo número de UCs e pela elevada carga letiva prática e clínica, os alunos de Licenciatura em OCV foram fortemente atingidos pela crise COVID-19. Apesar das dificuldades, o feedback dos alunos foi muito positivo durante todo o período de crise entre março e junho. Após um breve período inicial com alguma dificuldade, rapidamente os alunos adaptaram os seus métodos de estudo à nova realidade, contribuindo positivamente para melhor articulação e funcionamento das UCs. Tudo isto pode ser comprovado pelo elevado número de alunos presentes em cada sessão de aula síncrona (quase sempre superior a $85 \%$ ), bem como pela posterior visualização das aulas gravadas. A gravação das aulas permitiu aos alunos ver e/ou rever a aula e permitiu aos trabalhadores/estudantes o acompanhamento teórico que antes lhes era impossibilitado por questôes laborais.

Uma das inquietações desde o início desta nova metodologia de ensino prendia-se com as possíveis limitaçóes por parte de alguns alunos ao acesso a equipamentos e, principalmente, à possibilidade e qualidade do acesso a internet. Nesse seguimento, na segunda quinzena de março, foi realizado um inquérito aos alunos da Lic. OCV na UC de opção Optometria Funcional para aferir a qualidade de visualização das aulas síncronas online. Os alunos referiram que a ligação à internet para assistir às aulas remotamente era: "Boa, consigo realizar a maior parte das atividades" (41\%), ou "Muito boa, consigo realizar praticamente todas as tarefas" (59\%). Nenhum dos presentes na aula respondeu "Muito má, quase impossibilita as atividades", ou "Má, limita as minhas atividades". Não foram colocadas questôes relativamente aos dispositivos eletrónicos para participação nas aulas, mas de acordo com o que foi possível aferir, os alunos conseguiam aceder sem problema às aulas síncronas através de computador, tablet ou telemóvel. A direção de curso, em colaboração com os delegados de ano, identificou todas as situações de limitação e a título de exemplo, foi referenciado pelo Diretor de Curso da Licenciatura OCV ao Conselho Pedagógico da ECUM o caso de um aluno com dificuldades por ausência de dispositivo idóneo para o acompanhamento das aulas pelo que a UMinho através da iniciativa Alumni, cedeu um terminal PC portátil.

A perspetiva geral dos alunos para a qualidade do ensino mediado tecnologicamente durante a pandemia foi de um modo geral positiva. No dia 14 de maio foi 
realizado um inquérito na plataforma Blackboard aos alunos do 3 ano da Lic. OCV para aferir a sua perspetiva relativa à qualidade da experiência das aulas em acesso remoto. Neste caso, $71 \%$ dos alunos inquiridos classificaram a experiência como "Boa" ou "Muito Boa", ainda que $22 \%$ dos alunos tenham referido não ter opinião e $2 \%$ não responderam. Estes resultados encontram-se em consonância com alunos de outros países reportados em experiências semelhantes de lecionação à distância ${ }^{10}$ e11.

\section{A PERSPETIVA DOS DOCENTES}

À medida que se iam alargando as experiências crescia o entusiasmo por se estar a conseguir reagir positivamente e manter a atividade letiva, os docentes em articulação com os alunos foram-se apercebendo de dificuldades de diversa natureza, nomeadamente dificuldades de acesso por parte de alguns alunos (onde o docente se apercebia durante a aula que os alunos entravam e saiam da sessão constantemente), problemas de horário e sobrecarga de trabalho. Em colaboração com os delegados de ano e os alunos, rapidamente essas dificuldades foram identificadas e superadas, com os devidos ajustes/soluções que passaram por exemplo, pela gravação de todas as aulas síncronas ou assíncronas e a flexibilização na entrega dos trabalhos propostos, bem como pela criação de novos métodos e trabalhos de avaliação dos alunos.

A motivação dos alunos para interagir durante as aulas foi uma das maiores dificuldades com que os docentes se foram deparando durante este processo. Assim, para além do recurso a ferramentas de dinamização como quizzes já indicados anteriormente, foram também propostos inquéritos curtos no decorrer das sessões, com perguntas de escolha múltipla ou de resposta sim/não, disponível na plataforma $B b$. Alguns docentes optaram também por incluir a realização de pequenas apresentações orais ( 3 a $5 \mathrm{~min}$ ), por grupos de alunos, sobre temas previamente abordados na UC, para motivar os alunos para o estudo individual e participação ativa nas aulas síncronas online.

10 Herse P, Lee A (2005). Optometry and WebCT: a student survey of the value of web-based learning environments in optometric education. Clin Exp Optom. 88(1):46-52. https://doi.org/10.1111/j.1444-0938.2005. tb06663.x.

11 Suttle CM, Challinor KL, Thompson RE, et al. (2015). Attitudes and barriers to evidence-based practice in optometry educators. Optom Vis Sci. 92(4):514-523. https://doi.org/10.1097/OPX.0000000000000550. 
À medida que o cenário de não retorno a atividades presenciais até ao final do ano letivo se tornava mais real, a preocupação também crescia em relação aos alunos finalistas que teriam que terminar o curso sem um número importante de práticas laboratoriais essenciais para a aquisição de competências clínicas. Apesar de rapidamente se ter conseguido adequar uma parte do conteúdo das aulas práticas e do contexto laboratorial para ensino remoto, é reconhecido pelos docentes da área que uma grande parte do conteúdo prático em contexto clínico, fundamental para as competências dos alunos, só será possível realizar em formato presencial.

Esta pareceu ser também a perspetiva de uma larga maioria dos estudantes, que foram demonstrando as suas inquietações aos docentes ao longo das aulas síncronas. Um inquérito realizado aos alunos finalistas da LOCV, no final de maio de 2020, mostrou que perante a questão "Como vê a possibilidade de ter aulas práticas presenciais no final do semestre, 2 a 6 aulas entre junho e julho 2020”, 46\% dos alunos respondeu que "Certamente gostaria de ter essas aulas", $38 \%$ consideraram "Ser um risco controlado que vale a pena”, $4 \%$ consideraram "Apesar de ser positivo é um risco que não vale a pena” e 11\% "Não responde” (figura 3). Mais recentemente, foi elaborado um inquérito levado a cabo pela delegada do 3o ano junto dos colegas, de forma a aferir quais os maiores impedimentos/receios para um possível retorno a alguma atividade presencial ainda dentro do atual estado. Uma larga maioria concordava com o regresso à atividade laboral, sendo que os maiores motivos de preocupação eram as questões relacionadas com o transporte e alojamento. Naturalmente, esta opção estaria sempre dependente de existirem as condiçốes de segurança sanitária para se realizar, como posteriormente se veio a verificar. De facto, a possibilidade de lecionação e avaliação presencial foi colocada aos docentes para se poder vir a realizar entre junho e julho em casos muito bem justificados. Na Área de OCV sempre entendemos que este é um desses casos. 


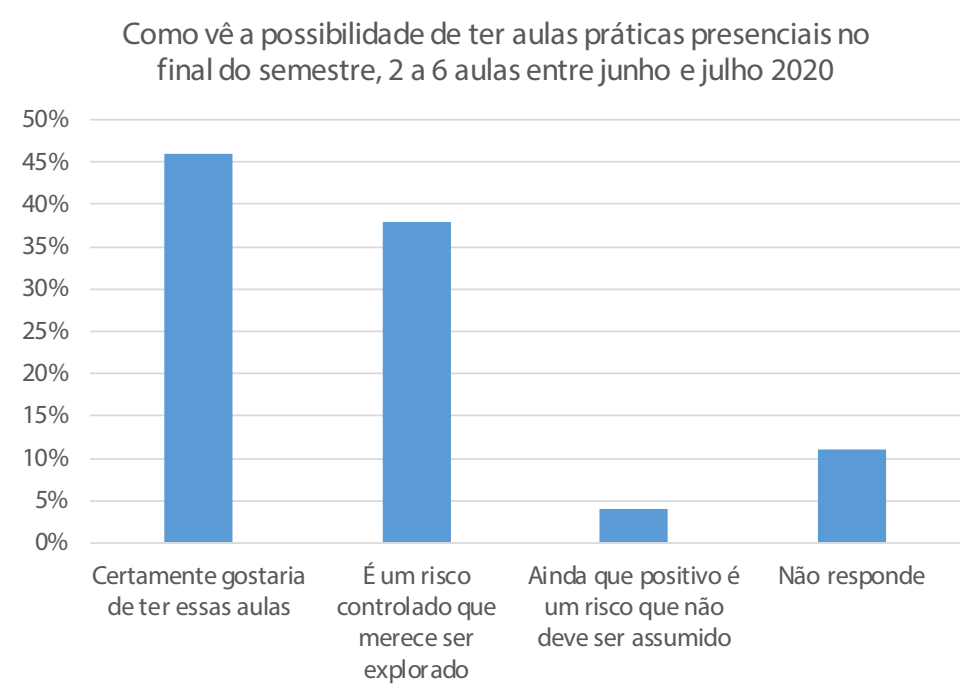

Figura 3. Resultados de um inquérito realizado a estudantes finalistas da licenciatura de OCV em maio de 2020.

\section{A AVALIAÇÃo}

Chegados a meio do semestre, e com a iminente impossibilidade de se realizar avaliação presencial, começou a antecipar-se a necessidade de dar resposta à avaliação dos estudantes tecnologicamente mediada. Para a grande maioria dos alunos e alguns docentes, a realização dos exames de avaliação remota na plataforma $B b$ Collaborative Ultra foi relativamente simples, uma vez que já estavam familiarizados com o processo de avaliação recorrendo a esta plataforma. Ao mesmo tempo esses docentes tiveram um papel ativo na migração dos restantes colegas para este tipo de avaliação. Este método de avaliação já havia sido previamente utilizado em diversas UCs em anos transatos, de forma presencial recorrendo às salas de computadores próprias das instalações da UMinho. Este modelo de avaliação remota foi aplicado quer para a realização dos exames de avaliação da componente teórica, mas também como ferramenta no incentivo ao estudo autónomo do aluno na preparação das aulas laboratoriais através da avaliação contínua dos protocolos de trabalho (minitestes já referidos anteriormente). Em algumas UCs foi também adicionado aos novos critérios de avaliação a realização de trabalhos com apresentação oral. Em outras UCs foi também adicionado a realização de pequenas tarefas ou exercícios, com submissão na plataforma $B b$ que serviram, não só como elementos de avaliação, mas também como fonte adicional de envolvimento dos alunos nos conteúdos da UC. 
O tema da avaliação foi também abordado pelo diretor do curso com os restantes docentes, nomeadamente para alinhamento de estratégias e critérios de uniformização entre as UCs, e para garantir as premissas de integridade académica. Assim, alguns docentes optaram por incorporar algumas das estratégias já usadas na elaboração dos exames não presenciais via plataforma $B b$. Foram aproveitadas as experiências prévias de avaliação presencial via blackboard nos laboratórios do $G A E$ e outras foram implementadas para minimizar a probabilidade de fraude. Os docentes optaram pela elaboração de vários bancos de perguntas, com diferentes graus de dificuldade, das quais apenas uma percentagem era exibida a cada aluno e foram também discutidas e estabelecidas orientações referentes ao tempo necessário para uma avaliação à distância (duração total do teste, tempo controlado para cada uma das questôes, aleatorização das opções de resposta, possibilidade ou não de retorno a questóes anteriores, tipo de questôes e que a aleatoriedade usada mantivesse critérios semelhantes, entre outras). De referir o importante contributo do $G A E$ na ajuda aos docentes na implementação das estratégias mencionadas através das diversas atividades realizadas (fóruns, webinars, blogue e atividade de suporte).

Os indicadores quantitativos de aproveitamento revelaram valores similares aos obtidos em anos anteriores em contextos de ensino e avaliação presencial. Nos casos específicos em que os docentes já realizavam testes e exames na plataforma Blackboard presencialmente nos laboratórios do $G A E$, observaram-se índices de aproveitamento similares aos realizados em avaliaçốes em contexto à distância sem a presença dos estudantes e docente na mesma sala. Embora não permita assegurar que se mantêm as mesmas premissas de integridade académica, a observação de que os resultados são similares permite considerar que é possível esperar resultados similares globalmente em contexto de ensino e avaliação remota.

\section{OUTRAS EXPERIÊNCIAS EUROPEIAS}

Existem atualmente mais de 40 instituições de ensino superior públicas e privadas que ministram cursos de graduação e pós-graduação na área de OCV em mais de 20 países na Europa. Através da European Academy of Optometry and Optics (EAOO), que conta com vários membros do corpo docente da UMinho nos seus 
órgãos, foi realizado na primeira semana de maio de 2020 um estudo sobre as perspetivas e práticas de ensino noutras instituições nacionais e internacionais que lecionam o mesmo tipo de cursos.

À data de suspensão das atividades (entre 10 e 18 de março) o semestre encontrava-se em níveis de evolução diferentes entre diferentes países. Enquanto em algumas instituições já tinham sido lecionadas 60 ou 80\% das aulas, na UMinho, tinham sido lecionadas apenas 33\% das aulas teóricas e aproximadamente $25-30 \%$ das aulas práticas. Neste mesmo estudo, $80 \%$ das instituições responderam que pelo menos 40 a $60 \%$ do semestre seria afetado pela situação pandémica e em $20 \%$ o grau de afetação foi de 80 a 100\% do semestre em curso. Em 70\% dos casos o semestre foi prolongado pelo menos 1 mês e em 30\% era previsto terminar dentro do prazo previsto. Apesar da assimetria, os resultados preliminares apontaram para uma elevada semelhança entre as práticas da UMinho e outras congéneres europeias. Em 80\% optaram por iniciar as atividades de substituição mediante ensino à distância nos 10 dias seguintes entre 12 e 23 de março e $80 \%$ fê-lo por indicação reitoral ou da Presidência da faculdade em questão. Quanto às aulas teóricas, todas as instituiçóes substituíram as aulas teóricas e os seminários por atividades mediadas tecnologicamente. Já para as aulas teórico-práticas, $70 \%$ das instituições implementaram a lecionação remota, enquanto que à data apenas 30\% tinham iniciado a lecionação de atividades práticas nessa modalidade. Todas as instituiçôes recorreram a plataformas de ensino já integradas na rede institucional (70\%) e/ou plataformas de acesso gratuito (90\%).

Quanto ao tipo de atividades utilizadas, 100\% referiram utilizar ensino síncrono enquanto 50\% referiram a utilização de ensino assíncrono. Em 90\% dos casos, a submissão de trabalhos através das plataformas foi também uma estratégia amplamente adotada.

Para dar resposta ao ensino clínico, $80 \%$ utilizaram a discussão de casos clínicos, $50 \%$ a demonstração de procedimentos através de vídeos, 30\% utilizaram plataformas de laboratórios virtuais e 30\% referiram não realizar qualquer atividade.

Perguntou-se ainda aos docentes que percentagem dos conhecimentos teóricos e das competências práticas seriam capazes de adquirir os alunos com base nas estratégias de ensino a distância. Tal como esperado, uma elevada proporção dos conhecimentos 
teóricos pode ser transmitida com recurso a ensino tecnologicamente mediado, mas essa mesma proporção é muito menor no que diz respeito às competências práticas. Isto não surpreende, uma vez que $70 \%$ dos casos consideraram que as instituições reconhecem a especificidade do ensino da optometria e consideram a lecionação presencial de parte dos conteúdos em algum momento até ao final do semestre. Pelo contrário, apenas $20 \%$ referia que, apesar de considerar a especificidade, não estava previsto haver qualquer exceção para esta especialidade quanto à lecionação presencial.

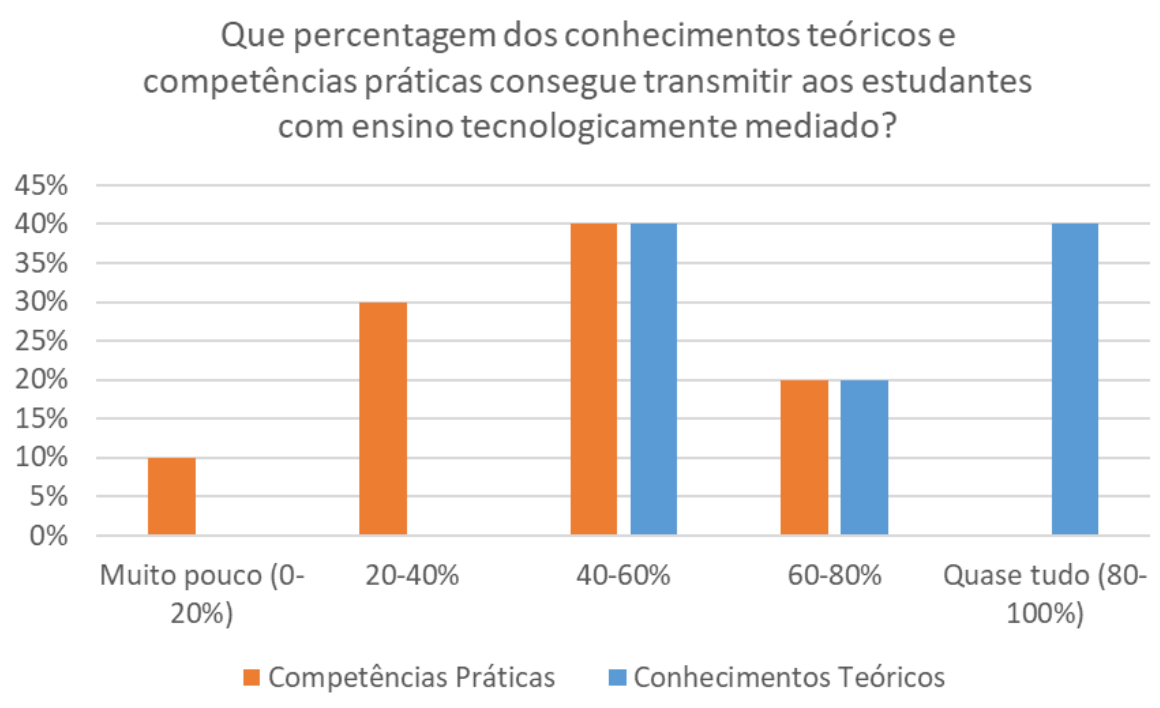

Figura 4. Perceção acerca da percentagem de conhecimentos (teóricos) e competências (práticas) que poderão ser alcançados em UCs da Área de OCV com recurso ao ensino tecnologicamente mediado.

Os resultados aqui reportados correspondem a um estudo piloto sendo que um estudo posterior mais alargado, e já numa fase mais avançada da pandemia (primeira quinzena de junho de 2020), revelou outras informações relevantes cujos resultados foram apresentados no Grupo de Interesse Especial (Special Interest Group - SIG) de Educação da EAOO no dia 19 de junho de 2020 e serão publicados proximamente em jornal internacional com revisão por pares.

Desta reflexão conjunta entre docentes de diferentes instituições em diferentes países surgiu a iniciativa de criar um banco de casos clínicos a nível europeu, centralizado na EAOO (European Academy of Optometry and Optics), de modo a fornecer 
material aos docentes para auxiliar no ensino à distância de práticas laboratoriais. Esta estratégia não poderia estar melhor alinhada com as práticas que se seguiram na Área Disciplinar de OCV, sendo que esta poderá beneficiar muito de estratégias deste género para a lecionação futura.

\section{O QUE MUdOU NA ÁREA DE OCV DA UMINHO E O QUE PODE FI- CAR PARA O FUTURO}

Toda esta nova experiência dos últimos meses permitiu aos docentes e alunos constatar que é possível uma rápida adaptação a novas circunstâncias e métodos de ensino. Foi também possível repensar se as estratégias de ensino utilizadas até ao início do ano 2020 seriam as melhores para todos os alunos. Esta situação permitiu abrir os horizontes e repensar as formas de ensino que podem vir a ser implementadas num futuro próximo. Quanto à área específica de OCV, o ensino pode passar por algumas mudanças nomeadamente a nível das aulas teóricas utilizando alguns dos recursos utilizados nesta fase. A ideia de que uma parte da componente teórica seja lecionada em modo remoto poderá permitir aos alunos acompanhar mais facilmente todos os conteúdos teóricos, nomeadamente os alunos que, pelos mais diversos motivos, não conseguem estar presencialmente nas aulas teóricas. A possibilidade de rever a aula a qualquer altura também poderá ser uma mais-valia para a assimilação dos conteúdos lecionados, estabelecendo assim uma simbiose entre o ensino síncrono, que pode ser reutilizado nalguns casos como material para o ensino assíncrono. Por outro lado, tendo o curso de OCV uma forte componente laboratorial de prática em contexto clínico, a utilização do ensino remoto poderá funcionar como introdução à explicação de procedimentos clínicos e dessa forma conseguir uma otimização das aulas presenciais, permitindo colmatar falhas individuais através de um ensino prático mais personalizado. No caso concreto, a inclusão do ensino prático baseado na evidência ${ }^{12}$, bem como o recurso à discussão, baseada

12 Bullock A, Barnes E, Ryan B, Sheen N (2014). Case-based discussion supporting learning and practice in optometry. Ophthalmic Physiol Opt. 34 (5): 614-621. https://doi.org/10.1111/opo.12151. 
na análise de casos clínicos, ${ }^{13}$ e 14 mostrou ser extremamente útil no apoio à aprendizagem prática em optometria.

Durante este período foram implementadas diversas estratégias para colmatar a ausência de aulas presenciais, algumas das quais entendemos que devem ser mantidas para o futuro.

Uma delas será a maior colaboração na partilha de materiais pedagógicos entre os docentes das diferentes UCs, incluindo vídeos laboratoriais gravados pelos próprios docentes, ou até mesmo partilha (depois de obtenção das devidas autorizaçôes) de recursos apenas acessíveis mediante assinatura e pagamento anual por parte de algum docente a título individual. Nos últimos meses, esta estratégia foi facilitada uma vez que algumas das entidades permitiram o livre acesso aos seus recursos.

À parte disso, a experiência dos últimos meses permitiu concluir que o uso de pequenos questionários durante a aula torna os alunos mais participativos e permite captar melhor a sua atenção. Deste modo, a exploração de novos modos de dinamização das aulas expositivas será essencial. O objetivo será procurar que os alunos interajam mais, por vezes utilizando os seus próprios telemóveis, tablets ou PCs.

Devem também, sempre que adequado, manter as atividades colaborativas entre os alunos para preparar e simular situações clínicas, com recurso às novas tecnologias. Foi possível fazer com que estudantes em locais distintos elaborassem vídeos que reproduziam o diálogo entre optometrista e paciente num contexto de consulta "virtual" que poderá ser explorado no futuro para a simulação de casos clínicos.

Naturalmente, as competências adquiridas pelos docentes neste contexto serão muito úteis num âmbito pedagógico a curto e médio prazo que se perspetiva em mudança. Aliás, esta mudança já se antecipava, com tendência para o aumento da oferta formativa em regime de ensino a distância ou regime misto. $\mathrm{O}$ contexto pandémico

13 Bullock A, Barnes E, Ryan B, Sheen N (2014). Case-based discussion supporting learning and practice in optometry. Ophthalmic Physiol Opt. 34(5):614-621. https://doi.org/10.1111/opo.12151.

14 Woodman-Pieterse EC, De Souza NJ, Vincent S J (2016). The influence of a novel simulated learning environment upon student clinical subjective refraction performance: A pilot study. Clin Exp Optom. 99 (4): 342-349. https://doi.org/10.1111/cxo.12374. 
veio acelerar este processo e capacitar um maior número de docentes para o exercício destas competências quer no âmbito da lecionação, quer no âmbito da avaliação.

Espera-se que de todas estas experiências sejamos mais resilientes a futuras eventualidades, mas acima de tudo que consigamos ser mais competitivos num contexto global em constante mudança e no qual as modalidades e regimes de ensino e aprendizagem estão também a mudar muito rapidamente. Esta é uma grande oportunidade para dar resposta à procura de formação por novos públicos que têm que conciliar a aprendizagem com a atividade laboral quer sejam aqueles que nos procuram desde locais distantes nos países de língua oficial portuguesa, como em outros países. 